\title{
Relationship between types of activity and subjective well-being in older adults living alone: Secondary analysis of the 2014 survey of attitudes towards older people living alone
}

\author{
Yuta Mori*1,2,3, Tomoki Tachi ${ }^{1}$ \\ ${ }^{1}$ Department of Rehabilitation, Hananooka Hospital, Japan \\ ${ }^{2}$ Faculty of Care and Rehabilitation, Seijoh University, Japan \\ ${ }^{3}$ Department of Public Health, Graduate School of Medicine, Chiba University, Japan
}

Received: August 24, 2020

DOI: $10.5430 /$ jer.v6n1p7
Accepted: September 14, 2020 Online Published: September 23, 2020

URL: https://doi.org/10.5430/jer.v6n1p7

\begin{abstract}
Objective: In the contemporary aging society, subjective well-being is an important determinant of quality of life for older adults living alone. Although the association between improved health and subjective well-being in this population is well documented, the types of activities associated with subjective well-being are unclear.

Methods: This study assessed the relationship between subjective well-being and activity types among older adults living alone based on a secondary analysis of the 2014 Survey of Attitudes Towards Older People Living Alone data. We conducted a Poisson regression analysis to determine the association between activity and subjective well-being.

Results: After adjustment for age, sex, subjective physical health, subjective mental health, and income, higher levels of subjective well-being were significantly associated with spending time with family, meeting friends, playing with pets, eating, hiking, traveling, and watching sports.

Conclusion: Going out and interactive activities, as well as individual activities outside the home, are associated with higher levels of subjective well-being. Promoting these activities has the potential to increase the subjective well-being of older adults.
\end{abstract}

Key Words: Living alone, Older adults, Subjective well-being, Physical health, Mental health

\section{INTRODUCTION}

Living alone while in retirement is increasingly common. In the United States, the percentage of people living alone has more than quadrupled since 1990 , with $26 \%$ of seniors living alone in 2014, representing 12.5 million people. ${ }^{[1]}$ In both Northwestern and Eastern Europe, an estimated 50\% of women aged $\geq 60$ years live alone. ${ }^{[2]}$ An increase in the number of older adults living alone has also been observed in
Japan $^{[3]}$ and China. ${ }^{[4]}$ Older adults who live alone are characterized by depressive tendencies ${ }^{[5]}$ and lonely and confined tendencies, ${ }^{[6]}$ and there is a need to improve social support and social networks by promoting participation in community activities, providing places and opportunities for people to have a sense of purpose in life, and providing opportunities to interact with friends and neighbors. In response to these life behaviors, subjective well-being has recently been

\footnotetext{
*Correspondence: Yuta Mori; Email: yuta.mori.89@gmail.com; Address: Department of Rehabilitation, Hananooka Hospital, Sun Life Inn 2, 1846-192 Kubo-cho, Matsusaka-shi, Mie, Japan.
} 
used as an indicator to measure the subjective quality of life of older adults. ${ }^{[7]}$ Subjective well-being can be defined as a subjective or psychological aspect of quality of life, and many researchers agree that there are two domains of the structure of subjective well-being: cognitive well-being and emotional well-being. ${ }^{[8]}$ Research on the factors that characterize subjective well-being has shown that, besides the risk of a diagnosed illness, ${ }^{[9]}$ life events, such as marriage and bereavement for a loved one, as well as environmental factors, such as income and sex, are known to have an impact. ${ }^{[10]}$ Furthermore, research on adults age $\geq 65$ years has reported that altruistic behaviors such as teaching skills and transferring knowledge to others are associated with higher subjective well-being. ${ }^{[7]}$ Specifically for older adults living alone, however, it is not known which types of activities are associated with subjective well-being among various activities, including activities of daily living such as eating and drinking, leisure activities such as television and radio, and social participation activities such as meeting with friends and chatting. This study aimed to discover what activities are associated with subjective well-being for older adults living alone. The significance of this study is that activity promotion for older adults living alone is a useful basis for a positive change in subjective well-being.

Table 1. Proportion of high subjective well-being based on the types of social activities

\begin{tabular}{|c|c|c|}
\hline $\mathbf{N}=\mathbf{1 2 4 0}$ & $\mathbf{N}$ & $\%$ \\
\hline TV, radio & 980 & 79 \\
\hline Video, $\mathrm{CD}$ viewing & 260 & 20.7 \\
\hline Newspapers, magazines & 563 & 45.4 \\
\hline Spending time with family and grandchildren & 243 & 19.6 \\
\hline Gather with friends, chat, socialize with friends and people with similar interests & 678 & 54.7 \\
\hline Play with pets such as dogs and cats & 130 & 12.5 \\
\hline Eating and drinking & 542 & 43.7 \\
\hline Shopping, window shopping & 380 & 30.6 \\
\hline Sports activities (swimming, tennis, golf, gateball, aerobics, etc.) & 227 & 18.3 \\
\hline Walking, jogging & 429 & 34.6 \\
\hline Hiking, mountaineering, camping, fishing, and other suitable treasures in the nature & 102 & 8.2 \\
\hline Traveling & 411 & 33.1 \\
\hline Reading & 321 & 25.8 \\
\hline Hobby activities mainly indoors (painting, calligraphy, handicraft, sewing, crafts, pottery, etc.) & 275 & 22.2 \\
\hline Hobby activities mainly outdoors (gardening, agriculture, etc.) & 227 & 18.3 \\
\hline Singing, dancing (Karaoke, folk song, chorus, musical instrument performance, ballroom dance) & 247 & 19.9 \\
\hline Watch sports, plays, concerts, movies & 266 & 21.5 \\
\hline Internet, word processor, personal computer, mobile phone & 114 & 9.2 \\
\hline Indoor entertainment (igo, shogi, Hanafuda, playing cards, mahjong, commercial games, etc.) & 83 & 6.7 \\
\hline Learning activities such as attendance of liberal arts courses & 97 & 7.8 \\
\hline Social service, volunteer activities & 109 & 8.8 \\
\hline Maintenance and preservation of traditional culture & 27 & 2.2 \\
\hline Religious activity, faith & 45 & 3.6 \\
\hline Work (occupation, family business) & 129 & 10.4 \\
\hline Educational activities (the position where I teach) & 22 & 1.8 \\
\hline
\end{tabular}

\section{MethodS}

\subsection{Data source}

In this study, a secondary analysis was conducted on data for the older adults living alone who were the previous participants of a large survey-the 2014 Survey on Attitudes Towards Older adults Living Alone, conducted by the Cabinet Office. This survey was a nationwide study of men and women aged $\geq 65$ years living alone. In-home interviews were conducted by the researcher with a planned sample of 2,624 participants selected by stratified two-stage random sampling. A survey method was used to conduct the study. The survey contained the following questions in the order: about basic attributes, happiness and anxiety, relationships with people, product purchases and scams, going out and visiting the hospital, 
preparing for the future, and activities and pleasures. The number of valid responses and collection rate was 1,480 or $56.4 \%$. In this study, 1,240 independent older adults who were not certified as needing nursing care were assessed.

\subsection{Subjective well-being}

Using subjective well-being as a measure of happiness, the participants were asked this question: "How happy are you currently?" A total of 11 options were provided for the respondents, ranging from a score of 0 (very unhappy) to 10 (very happy). Furthermore, those who responded on a scale of 0 to 7 points from a previous study 7 were classified as having low subjective well-being, and those who responded on a scale of 8 to 10 points were classified as having high subjective well-being.

\subsection{Explanatory variables}

For the explanatory variables, the participants were asked this question: "What do you enjoy doing in your daily life?" The range of responses is shown in Table 1. For each of these items, the corresponding "yes" and "no" values were set as binary values.

\subsection{Covariates}

Research has shown that factors associated with well-being include age, sex, subjective physical health, subjective mental health, and economic status. ${ }^{[11]}$ Based on these findings, the variables for this current study assumed to be associated with subjective well-being were age, sex, subjective physical health, subjective mental health, and income. Age was set as a binary value for the early older age (65-74 years) and late older age ( $\geq 75$ years). To determine the income, the participants were asked this question: "How much money do you earn each month? Please tell us the amount of money you earn, including your pension, and including tax." The options in dollars (\$) given were > 300, 300-499, 500-999, $1,000-1,499,1,500-1,999,2,000-2,999$, and $\geq 3,000$. For the seven choices of $000 \leq$; $\geq 999 ; 1,000-1,999,<2$, the three values were set at zero dollars $(\$ 0)$.

\subsection{Analytical methods}

To determine the subjective well-being scores, the covariates among the low-subjective well-being and high-subjective well-being groups and by the number of participants in each activity served as an explanatory variable. The risk ratios and $95 \%$ confidence intervals for the subjective well-being of the high-subjective well-being group compared with those of the low-subjective well-being group were determined. The study participants who had a higher subjective well-being of $\geq 10 \%$, and logistic regression analysis showed that the risk ratio for the odds ratio could not be estimated accurately. ${ }^{[12]}$ Therefore, Poisson regression analysis was used. Published by Sciedu Press
The associations between the explanatory variables were also assessed using the polychoric correlation coefficient.The data software programs SPSS 24.0J (IBM) and STATA/MP 16.0 (Stata Corp., College Station, TX) were used for statistical analysis, and the significance level was set at $5 \%$.

\section{RESULTS}

Table 2 shows the distribution of subjective well-being among study participants, with the highest value of 351 (28.3\%) respondents scoring 5 points, followed by 177 (14.3\%) with 10 points, $182(14.7 \%)$ with 8 points, and 7 (13.3\%) with 165 points. Study participants with subjective well-being were divided into two groups: 447 (36.0\%) in the happy group and $793(64.0 \%)$ in the non-happy group.

Table 2. Distribution of subjective well-being among participants

\begin{tabular}{lll}
\hline Subjective well-being score & $\mathbf{N}$ & \% \\
\hline 0 & 7 & 0.6 \\
1 & 12 & 1 \\
2 & 14 & 1.1 \\
3 & 51 & 4.1 \\
4 & 50 & 4 \\
5 & 351 & 28.3 \\
6 & 143 & 11.5 \\
7 & 165 & 13.3 \\
8 & 182 & 14.7 \\
9 & 88 & 7.1 \\
10 & 177 & 14.3 \\
Total & 1,240 & 100.0 \\
\hline
\end{tabular}

In terms of each activity, the highest values were 980 (70.9\%) for television and radio; 678 (54.7\%) for meeting with friends, chatting, and socializing with friends and people with the same interests; $563(45.4 \%)$ for newspapers and magazines; and 542 (43.7\%) for eating and drinking (see Table 1). The results of the Poisson regression analysis are shown in Table 3. Adjusting for the covariates of age, sex, subjective physical health, subjective mental health, and income, spending time with family, meeting with friends, playing with pets, eating and drinking, hiking, traveling, and watching sports were significantly associated with higher levels of subjective well-being. Table 4 shows the results with correlation coefficients 0.5 and above. Correlation analysis revealed high correlations between social participation activities, such as "Learning activities such as attending liberal arts courses" and "Social service, volunteer activities", and between outside activities, such as "Traveling" and "Watch sports, plays, concerts, movies". 
Table 3. Relationship between subjective well-being and types of social activities

\begin{tabular}{|c|c|}
\hline & $N=1240$ \\
\hline $\mathrm{TV}$, radio & $0.92(0.74-1.15)$ \\
\hline Video, $\mathrm{CD}$ viewing & $1.08(0.86-1.34)$ \\
\hline Newspapers, magazines & $0.99(0.82-1.20)$ \\
\hline Spending time with family and grandchildren & $1.34(1.09-1.66)^{* *}$ \\
\hline Gather with friends, chat, socialize with friends and people with similar interests & $1.29(1.06-1.58)^{*}$ \\
\hline Play with pets such as dogs and cats & $1.32(1.01-1.73)^{*}$ \\
\hline Eating and drinking & $1.24(1.03-1.50)^{*}$ \\
\hline Shopping, window shopping & $1.14(0.94-1.39)$ \\
\hline Sports activities (swimming, tennis, golf, gateball, aerobics, etc.) & $1.14(0.91-1.42)$ \\
\hline Walking, jogging & $1.15(0.95-1.39)$ \\
\hline Hiking, mountaineering, camping, fishing, and other suitable treasures in the nature & $1.41(1.04-1.91)^{*}$ \\
\hline Traveling & $1.26(1.04-1.53)^{*}$ \\
\hline Reading & $1.12(0.92-1.37)$ \\
\hline Hobby activities mainly indoors (painting, calligraphy, handicraft, sewing, crafts, pottery, etc.) & $1.18(0.96-1.46)$ \\
\hline Hobby activities mainly outdoors (gardening, agriculture, etc.) & $1.12(0.89-1.40)$ \\
\hline Singing, dancing (Karaoke, folk song, chorus, musical instrument performance, ballroom dance) & $1.11(0.90-1.39)$ \\
\hline Watch sports, plays, concerts, movies & $1.25(1.02-1.54)^{*}$ \\
\hline Internet, word processor, personal computer, mobile phone & $1.28(0.97-1.70)$ \\
\hline Indoor entertainment (igo, shogi, Hanafuda, playing cards, mahjong, commercial games, etc.) & $1.14(0.80-1.65)$ \\
\hline Learning activities such as attendance of liberal arts courses & $1.12(0.83-1.51)$ \\
\hline Social service, volunteer activities & $1.17(0.88-1.56)$ \\
\hline Maintenance and preservation of traditional culture & $1.30(0.79-2.15)$ \\
\hline Religious activity, faith & $1.37(0.92-2.04)$ \\
\hline Work (occupation, family business) & $1.22(0.91-1.63)$ \\
\hline Educational activities (the position where I teach) & $1.40(0.82-2.39)$ \\
\hline
\end{tabular}

Note. $* * \mathrm{p}<.01 * \mathrm{p}<.05$. We adjusted for sex, age, equivalent monthly income, subjective physical health, subjective mental health using Poisson regression models. Figures in the table are prevalence ratios ( $95 \%$ confidence intervals).

Table 4. Relationship between subjective well-being and types of social activities

\begin{tabular}{lll} 
Two explanatory variables & & Correlation coefficient \\
\hline Newspapers, magazines & Reading & 0.52 \\
Eating and drinking & Shopping, window shopping & 0.556 \\
Traveling & Watch sports, plays, concerts, movies & 0.515 \\
Watch sports, plays, concerts, movies & Learning activities such as attending & 0.538 \\
Learning activities such as attending liberal arts courses & liberal arts courses & 0.558 \\
Learning activities such as attending liberal arts courses & $\begin{array}{l}\text { Maintenance and preservation of } \\
\text { traditional culture }\end{array}$ & 0.546 \\
Learning activities such as attending liberal arts courses & Educational activities & 0.593 \\
Social service, volunteer activities & Educational activities & 0.64 \\
Maintenance and preservation of traditional culture & Educational activities & 0.526 \\
\hline
\end{tabular}




\section{Discussion}

This study was designed to determine what activities are associated with subjective well-being for older adults living alone. The results were clear that spending time with family, meeting with friends, playing with pets, eating and drinking, hiking, traveling, and watching sports were significantly associated with higher levels of subjective well-being. In research that previously examined the subjective well-being of community-dwelling older adults aged $\geq 65$ years, participants scored between 8 and 10 points on the subjective well-being survey, representing $53.9 \%$ of the total respondents, ${ }^{[7]}$ compared with $36 \%$ of the respondents in the current study. Furthermore, other studies have classified the types of leisure activities by cluster analysis, which showed four types: individual outings, individual home-based activities, outing/home activities, and individual home-based activities. The number of activities such as outings was found to be related to the subjective well-being of older adults. ${ }^{[13]}$ In the current study, which was limited to older adults living alone, results showed that meeting with friends, hiking, traveling, and it was found that many of the participants were involved in "going out and interacting" or "going out on their own" activities, such as watching sports. In my study, correlational analyses showed high correlations in outside activities such as "Traveling" and "Watch sports, plays, concerts, movies". These results suggest that older adults living alone may show a similar trend to previous studies in clustering activities. In happiness studies, the frequency of conversation was found to be a happiness factor for older adults living alone. ${ }^{[11]}$ In contrast, for this population, not having anyone to turn to in times of need. ${ }^{[14]}$ Experiencing loneliness, and facing an insecure living environment contributed to unhappiness. ${ }^{[15]}$ In this study, for the activities associated with the subjective well-being group, the opportunities for conversation, such as spending time with family and meeting with friends, represented a large number of activities. The time spent doing these activities made it possible to enhance social support and social networks. These results suggest that these types of activities were significantly associated with higher subjec- tive well-being. Besides these social activities, hiking and traveling are characterized by movement, and it is possible that impressions of the landscape while moving through it can influence feelings of well-being and positive emotions during the activity. This study has several limitations. The first is that the study design was cross-sectional, limited in the number of people included, and causal. The second point is that lone men are at risk of needing care because of the support they provide to others. Further, $24 \%$ less $^{[16]}$ and men who live alone are 2.7 times more likely to be depressed when eating alone it has been reported that it is easy, ${ }^{[17]}$ but considering the number of subjects, stratified analysis has not been conducted. Third, unmeasured factors, such as the number of years living alone, pension type, education history, and social support may affect the results. In the future, these considerations must be taken into account when conducting analyses. Additionally, items with high correlation coefficients were found among some of the explanatory variables. This requires advanced cluster analysis to search for common factors, followed by regression analysis. Results of this study show that spending time with family, meeting with friends, playing with pets, eating and drinking, hiking, traveling, and watching sports, even after adjusting for age, sex, subjective physical health, subjective mental health, and income, were all significantly associated with higher levels of subjective well-being. These results are expected to aid in policy formulation and assistance for older adults living alone. Longitudinal studies should be used to determine the causal relationship in the future.

\section{ACKNOWLEDGements}

The SSJ Data Archive, the Center for Social Surveys and Data Archiving at the Institute of Social Science, University of Tokyo, provided the individual data from the "Survey on Attitudes toward Older adults Living Alone, 2014" (attached to the Cabinet Office's Policy Director (Social Policy) in charge of Aging Society).

\section{CONFlicts OF InTEREST Disclosure}

The authors declare that they have no competing interests.

\section{REFERENCES}

[1] Stepler R. Smaller share of women ages 65 and older are living alone before and after age adjustment. Washington, DC: Pew Center 2016.

[2] Jamieson L, Simpson R. Living alone: globalization, identity and belonging. Berlin: Springer; 2013. https ://doi .org/10.1057/ 9781137318527

[3] Brown JW, Liang J, Krause N, et al. Transitions in living arrangements among elders in Japan: does health make a difference? J Geron- tol B Psychol Sci Soc Sci. 2002; 57: S209-S220. PMid:12084791. https://doi.org/10.1093/geronb/57.4.S209

[4] Lei X, Strauss J, Tian M, et al. Living arrangements of the elderly in China: evidence from the CHARLS national baseline. China Economic J. 2015; 8: 191-214. PMid:27182281. https : //doi.org/10.1080/17538963.2015.1102473

[5] Stahl ST, Beach SR, Musa D, et al. Living alone and depression: the modifying role of the perceived neighborhood environ- 
ment. Aging Ment Health. 2017; 21: 1065-1071. PMid:27267633. https://doi.org/10.1080/13607863.2016.1191060

[6] Klinenberg E. Social isolation, loneliness, and living alone: identifying the risks for public health. Am J Public Health. 2016; 106 786-787. PMid:27049414. https://doi.org/10.2105/AJPH. 2 016.303166

[7] Hirotaka N, Chiyoe M, Yoshihiko Y. Social activities and subjective well-being among older persons in Japan. J Epidemiol Res. 2019; 5: 56-62. https ://doi .org/10.5430/jer.v5n1p56

[8] Diener E, Suh EM, Lucas RE, et al. Subjective well-being: three decades of progress. Psychol Bull 1999;125:276-302. https://do i.org/10.1186/s13690-017-0207-7

[9] Kaufmann EG, Engel SA. Dementia and well-being: A conceptual framework based on tom Kitwood's model of needs. Dementia. 2016 15(4): 774-788. PMid:24948470. https ://doi.org/10.1177/14 71301214539690

[10] Clark AE, Oswald AJ. Satisfaction and comparison income. J Public Econ. 1996; 61: 359-381. https://doi.org/10.1016/0047-2 727 (95) 01564-7

[11] Miyuki O. Study on well-being of the elderly living alone. Review of Hakodate University. 2018; 49: 99-121.
[12] Zhang J, Yu KF. What's the relative risk? A method of correcting the odds ratio in cohort studies of common outcomes. JAMA. 1998; 280: 1690-1691. PMid:9832001. https://doi.org/10.1001/jama.2 80.19 .1690

[13] Seiji H, Naoya A. A study on the relationship between the leisure avtive and the feeling of happiness of aged person. JSCE. 2015; 71: 567-576. https://doi.org/10.2208/jscejipm.71.I_567

[14] Natsuki K, Haruna S, Syusaku N, et al. The impact of daily travel on subjective well-being. JSCE. 2011; 67(5): 697-703. https: //doi.org/10.2208/jscejipm.67.67_I_697

[15] Kyoko S, Etsuko F. The review on the condition can continue living healthy elderly people living alone. Jpn J Nurs Sci. 2019; 5: 921-932.

[16] Saito T, Murata C, Aida J, et al. Cohort study on living arrangements of older men and women and risk for basic activities of daily living disability: findings from the AGES project. BMC Geriatr. 2017; 17 : 183. PMid:28814289. https://doi .org/10.1186/s12877-017 $-0580-7$

[17] Tani Y, Sasaki Y, Haseda M, Kondo K, Kondo N. Eating alone and depression in older men and women by cohabitation status: the JAGES longitudinal survey. Age Ageing. 2015; 44: 1019-1026. PMid:26504120. https://doi .org/10.1093/ageing/afv145 